\title{
The Yngve Ericsson Prize in Preventive Odontology
}

\section{Call for Nominations}

The Swedish Patent Revenue Fund for Research in Preventive Odontology was established in 1963. Among several activities to support research in this field, the Fund every third year awards a major international prize named in honour of its founder and major donator, professor Yngve Ericsson, one of the founders of ORCA.

The recipient should be an eminent researcher in the field of preventive odontology. The Prize was instituted in 1986 in collaboration with the Swedish Medical Research Council.

Beginning in 2010 the Prize has been awarded in collaboration with ORCA, the European Organization for Caries Research.

The following researchers have in the past received the Yngve Ericsson Prize: Harold Hodge and Finn Brudevold (1988); Gunnar Rølla and Arje Scheinin (1991); Bo Krasse and Jan Lindhe (1994); William Bowen and Thomas Marthaler (1997); Bob ten Cate and Sigmund Socransky (2000); John Featherstone and Ole Fejerskov (2003); Adrian Lussi and Jorma Tenovuo (2006); Jaime A. Cury and Hannu Hausen (2010); and Vibeke Bælum and Bente Nyvad (2013).

The next Prize is to be presented to the awardee(s) at the ORCA Congress in Athens, Greece, in July 2016. The
Patent Revenue Fund and ORCA herby solicit nominations for the 2016 Yngve Ericsson Prize. The award will be SEK 300,000 (approx. EUR 32,000) for one person and SEK 200,000 per person if shared by two recipients.

The Prize winner(s) will be selected by a Prize Committee of distinguished scientists, three members of which are appointed by the Patent Revenue Fund for Preventive Odontology and two members appointed by ORCA.

The Prize is awarded to persons who have performed outstanding laboratory or clinical research that has contributed specifically to the prevention of dental and oral disease. Candidates are judged on the originality, quality and range of their scientific contributions as well as the range and clinical importance of the results. Individuals who are still active in research are preferred candidates.

No preference will be given to candidates from any country. A nomination should contain the name of the candidate and must be accompanied by a statement giving reasons why the candidate would be a worthy awardee, including a list of the candidate's relevant scientific publications and, if possible, a short CV.

Nominations of candidates must be received by the Secretary of the Patent Revenue Fund, Prof. Peter Lingström (Institute of Odontology, Box 450, SE-405 30 Göteborg, Sweden; E-Mail peter.lingström@odontologi. gu.se), no later than February 15, 2016. 